Article

\title{
Is It All about Efficiency? Exploring Students' Conceptualizations of Sustainability in an Introductory Energy Course
}

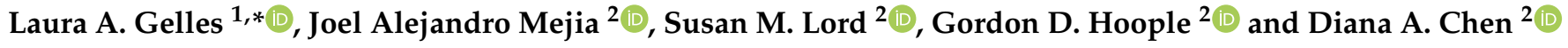 \\ 1 Erik Jonsson School of Engineering and Computer Science, University of Texas at Dallas, \\ Richardson, TX 75080, USA \\ 2 Integrated Engineering, Shiley-Marcos School of Engineering, University of San Diego, \\ San Diego, CA 92110, USA; jmejia@sandiego.edu (J.A.M.); slord@sandiego.edu (S.M.L.); \\ ghoople@sandiego.edu (G.D.H.); dianachen@sandiego.edu (D.A.C.) \\ * Correspondence: laura.gelles@utdallas.edu
}

check for updates

Citation: Gelles, L.A.; Mejia, J.A.; Lord, S.M.; Hoople, G.D.; Chen, D.A. Is It All about Efficiency? Exploring Students' Conceptualizations of Sustainability in an Introductory Energy Course. Sustainability 2021, 13, 7188. https://doi.org/10.3390/ su13137188

Academic Editors: Jan E. DeWaters and Angela R. Bielefeldt

Received: 28 May 2021

Accepted: 22 June 2021

Published: 26 June 2021

Publisher's Note: MDPI stays neutral with regard to jurisdictional claims in published maps and institutional affiliations.

Copyright: (c) 2021 by the authors. Licensee MDPI, Basel, Switzerland. This article is an open access article distributed under the terms and conditions of the Creative Commons Attribution (CC BY) license (https:/ / creativecommons.org/licenses/by/ $4.0 /)$.

\begin{abstract}
Engineers are increasingly called on to develop sustainable solutions to complex problems. Within engineering, however, economic and environmental aspects of sustainability are often prioritized over social ones. This paper describes how efficiency and sustainability were conceptualized and interrelated by students in a newly developed second-year undergraduate engineering course, An Integrated Approach to Energy. This course took a sociotechnical approach and emphasized modern energy concepts (e.g., renewable energy), current issues (e.g., climate change), and local and personal contexts (e.g., connecting to students' lived experiences). Analyses of student work and semi-structured interview data were used to explore how students conceptualized sustainability and efficiency. We found that in this cohort $(n=17)$ students often approached sustainability through a lens of efficiency, believing that if economic and environmental resources were prioritized and optimized, sustainability would be achieved. By exploring sustainability and efficiency together, we examined how dominant discourses that privilege technical over social aspects in engineering can be replicated within an energy context.
\end{abstract}

Keywords: sustainability; efficiency; sociotechnical; engineering; energy education; undergraduate students; qualitative research

\section{Introduction}

The National Academy of Engineering has identified fourteen "grand challenges" for engineers of the 21st century to improve life on the planet. One of the four crosscutting themes of these challenges is sustainability [1]. Sustainability, broadly, has been described as the ability to meet the needs of the present without compromising the ability of future generations to meet their own needs. Sustainability balances three aspects (i.e., economic, environmental, and social responsibility) which form a Triple Bottom Line that accounts for the competing interests of various stakeholders [2]. A sustainable design has been defined as one in which resources must be used efficiently and responsibly to produce a profit (i.e., the economic aspect), the consumption of natural resources must be done at a rate that these resources can be replenished (i.e., the environmental aspect), and designs must remedy social inequities and provide fairness in distribution and opportunity that considers social aspects such as health, education, and gender and racial equity (i.e., the social responsibility aspect) [3]. Thus, this framing of sustainability allows for countries to align with the ideology of progressing economically and socially without destroying environmental resources, and stipulate that this development must be socially just [2]. Combining this conceptualization of sustainability with traditional engineering problem solving approaches focused on optimization and efficiency can implicitly treat 
the environment, society, and the economy as separate and competing [4]. Because these factors are conceptualized as separate, they cannot all be optimized at the same time. This results in some factors being prioritized over others. Profit-seeking companies often defer to the economic bottom line for short-term economic gain at the expense of environmental or social costs.

Traditional engineering problem solving approaches focused on optimization can be reductionist and thus incongruent with the principles of sustainability because the larger context is ignored when defining boundaries and constraints. In fact, creating boundaries opens the gates to deliberately defining what should be considered in engineering work, or what counts as valuable in engineering [5,6]. Optimization requires tradeoffs, maximizing desirable effects while minimizing undesirable effects [7]. In practice, one aspect inevitably takes precedence at the expense of others based upon the preferences of the client. While economic cost is not always the primary optimization criteria, optimizing in terms of cost is seen as a universal good, while other optimizations are relative and involve adjustments [8]. For example, optimizing for the lowest economic cost has resulted in decisions to place coal power plants in locations that predominantly affect racial minorities, leaving them to bear the costs of adverse health effects and premature death from breathing in hazardous particulate matter [9]. Adding to this problem, social impacts can be difficult to assess using these methods because they are challenging to quantify, unlike economic and environmental impacts, which have well-defined methods such as Design and Life Cycle Costing [10] and Environmental Life Cycle Analysis [11]. Due to the difficulty of quantification, social impacts typically are either superficially considered or left out of engineering problem solving altogether.

Inherent in many engineering problem solving approaches is a focus on efficiency, where efficiency is defined as the ratio of an output (such as energy or power) to an input. Efficiency is both a goal and a tool that engineers use to solve problems and takes precedence for primarily decision-making criteria. This valuation of efficiency often pervades engineering students' attitudes towards sustainability $[8,12,13]$. When considering sustainability, preserving resources for future use requires the efficient utilization of those resources. However, these sustainability-related efficiencies are often in opposition to economic efficiencies important to industry. This is one reason so many economists are in favor of adding a tax on carbon [14]. Even when not explicitly stated in the classroom, undergraduate engineering students are aware of this prioritization of economic aspects of sustainability [15]. In a study of mechanical engineering students' conceptualizations of sustainability, the majority of students focused on resource efficiency and described sustainability's relationship to engineering as designing "in a way that minimizes the use of resources or energy" ([13], p. 5), alluding to the idea that sustainable work should lead to higher profitability. It is noteworthy to add that social aspects were absent in these students' definitions of sustainability.

To truly address sustainability, a sociotechnical approach within engineering education is necessary. This approach deliberately infuses context (e.g., social, environmental) into engineering curricula so that students see how social contexts and technical problems combine and shape each other $[16,17]$. At the same time, having students engage with contextual factors prepares them for the skills and competencies they need upon graduation, as specified in ABET student outcomes \#2 and \#4 [18].

(2) an ability to apply engineering design to produce solutions that meet specified needs with consideration of public health, safety, and welfare, as well as global, cultural, social, environmental, and economic factors.

(4) an ability to recognize ethical and professional responsibilities in engineering situations and make informed judgments, which must consider the impact of engineering solutions in global, economic, environmental, and societal contexts.

We took a sociotechnical approach in our undergraduate engineering class, An Integrated Approach to Energy, in the hope that teaching students more integrated approaches 
will lead to them selecting design choices which are more socially and environmentally just [4]. This paper explores how sustainability was conceptualized in relation to efficiency by students in this class, and the resulting unintentionally replicated social/technical dualism observed in the classroom. The study is part of a larger investigation of the ways in which students respond to new integrated approaches in the engineering curriculum by purposefully challenging dominant discourses within engineering (e.g., prioritizing technical aspects over social ones) that privilege White, masculine, Western, and colonial ways of knowing $[19,20]$.

\section{Classroom Context}

An Integrated Approach to Energy is a second-year undergraduate engineering course that was offered for the first time during the Spring 2020 semester at a small private university in the western United States. This class intentionally employed an interdisciplinary and sociotechnical approach to teaching and emphasized modern energy concepts (e.g., renewable energy), current issues (e.g., climate change), and local and personal contexts (e.g., connecting to students' lived experiences). By doing so, we hoped students would be able to solve engineering problems related to energy concepts by building on contemporary challenges related to energy resources and examples from their everyday life. Eighteen undergraduate students enrolled in this course (one student did not consent to being included in this research) from a relatively new engineering major housed in the Department of Integrated Engineering (IntE). IntE features a flexible degree path where students can select concentrations (e.g., sustainability, biomedical engineering) that align with their personal and professional interests while taking engineering courses which highlight interdisciplinary engineering science through a sociotechnical lens. Developing this course was a multidisciplinary effort which drew on backgrounds within civil engineering, mechanical engineering, electrical engineering, and materials science to modernize energy curricula and counter the traditionally siloed approach to teaching energy within engineering disciplines. The course content was divided into four themes: (1) Energy Fundamentals, (2) Energy Generation, (3) Energy Policy, and (4) Energy Consumption. Select course objectives are provided in Table 1. The development and implementation of this class is further described in [21].

Table 1. Select course objectives for An Integrated Approach to Energy.

\begin{tabular}{|c|c|}
\hline & Selected Course Objective \\
\hline A & $\begin{array}{l}\text { Identify, formulate, and solve engineering problems related to a range of energy concepts (e.g., efficiency, heat, work, } \\
\text { and appropriate units) }\end{array}$ \\
\hline B & $\begin{array}{l}\text { Explain the fundamental operating principles of the most common types of electricity generation in California (e.g., } \\
\text { natural gas, solar, hydroelectric, nuclear, and wind) }\end{array}$ \\
\hline C & $\begin{array}{c}\text { Describe contemporary challenges caused by or related to energy resources, such as economic impacts, sociopolitical } \\
\text { tensions, and environmental impacts }\end{array}$ \\
\hline D & Apply concepts from class to inform decisions about energy consumption or conservation in your everyday life \\
\hline
\end{tabular}

The class met twice a week in person until the abrupt shift to Emergency Remote Teaching (ERT) as a result of the COVID-19 pandemic necessitated a shift to online instruction using Zoom. Active learning techniques such as "think, pair, share" and discussion were emphasized within this class when in person and adapted to an online format using Zoom breakout rooms, Google Docs, and Slack. More information about the transition to ERT for this class can be found in [22]. Demographic information about the students is provided in Table 2. 
Table 2. Student demographics for An Integrated Approach to Energy. All students majored in IntE and had a specific concentration.

\begin{tabular}{ccccccccc}
\hline \multicolumn{2}{c}{ Classification } & \multicolumn{2}{c}{ Sex } & & \multicolumn{3}{c}{ Concentration } \\
\hline $\begin{array}{c}\text { Second } \\
\text { Year }\end{array}$ & Third Year & Female & Male & Sustainability & $\begin{array}{c}\text { Embedded } \\
\text { Software }\end{array}$ & $\begin{array}{c}\text { Individual Plan of } \\
\text { Study }\end{array}$ & Biomedical & Law \\
\hline 17 & 1 & 6 & 12 & 8 & 5 & 3 & 1 \\
\hline
\end{tabular}

\section{Methods}

\subsection{Research Participation and Collected Data}

This study was situated within a larger research project focused on this class [21,23]. Student work (e.g., in-class activities, homework) and semi-structured interview data were used to explore how sustainability and efficiency were conceptualized and received by students. Students were required to participate in in-class activities, and complete homework and exam questions, but could opt out of having their responses included within the research. To protect participant confidentiality, pseudonyms were assigned to all students at the start of the semester by the researchers and used in all data collection (e.g., interviews) [24]. Informed consent was obtained on the first day of class [25]. Table 3 describes the data sources that were collected and that generated data relevant to this study. Researcher reflections and memos were used to triangulate the qualitative data. The transition to remote learning also necessitated a change in data collection methods. Further detail is provided below.

Table 3. Summary of data used for analysis.

\begin{tabular}{|c|c|c|}
\hline Data Source & Description & Example Question \\
\hline Student Work (17 students) & $\begin{array}{l}\text { In-class written prompts, end of class } \\
\text { student reflections, student homework } \\
\text { responses }\end{array}$ & $\begin{array}{l}\text { Prompt: What is efficiency? } \\
\text { In-class free write prompt: What trade-offs } \\
\text { should engineers consider when choosing } \\
\text { the source of energy for a new power station? } \\
\text { Homework reflective question: Consider the } \\
\text { material we have explored in class this week. } \\
\text { How has it changed your perspectives on } \\
\text { wind energy? Do you think wind energy will } \\
\text { be an important part of the energy landscape } \\
\text { in your lifetime? }\end{array}$ \\
\hline Interviews (11 students) & $\begin{array}{l}\text { Individual semi-structured student } \\
\text { interviews conducted over Zoom specific } \\
\text { to the Reimagining Energy course }\end{array}$ & $\begin{array}{l}\text { What was the most important thing you } \\
\text { learned from the class, and why? }\end{array}$ \\
\hline
\end{tabular}

\subsubsection{Student Work}

Student work data in the form of in-class written prompts/free writes, end of class reviews, student homework responses, and collaborative Google Docs were collected. Inclass prompts were utilized as a pedagogical tool to introduce concepts such as energy and efficiency and have students discuss these concepts with each other and then with the whole class, and to allow students to give feedback on course topics that they did not understand. End of class reviews and student homework assignments prompted students to reflect on the curriculum topics. Students were required to complete weekly homework assignments with reflective questions at the end of each assignment, which required students to consider how the course's content was relevant to their lives. Collaborative Google Docs allowed for students in different breakout rooms during class to work together in a remote setting with the instructor able to follow students' progress without interrupting [20]. Examples of these prompts, reflections, and homework questions are provided in Table 3. 


\subsubsection{Interviews}

Semi-structured interviews were conducted remotely over Zoom after the transition to ERT. This method provides a structure of pre-determined interview questions and also incorporates flexible follow-up questions based upon participant responses [26,27]. This protocol was developed by the authors based upon their experience and research on incorporating social context into engineering. The interviews were designed to be brief, develop rapport, and elicit participant perspectives on engineering, the class, and what aspects of engineering design they prioritize (e.g., social, technical). We included questions that indirectly elicited this information in order to mitigate positive bias in participants' responses. For example, we asked students to imagine they were designing a power installation and asked what information they needed to inform their design. What participants mentioned first, most frequently, and with the most detail conveyed authentic value and importance. The protocol was piloted with an undergraduate engineering student researcher to test the wording, understanding, and placement of questions. A copy of the interview protocol may be found in the Supplementary Material.

Eleven (six male, five female) students in the class opted to participate in semistructured interviews. Students were informed of the opportunity to participate in these interviews during class over Zoom by their instructor and provided with a link to a Google form where they could sign up to participate. Participating students were individually emailed by the postdoctoral researcher to set up a time to interview. Interviews ranged from 30-60 min and participants were compensated with a \$50 gift card. Interviews were recorded in Zoom and transcribed using TranscribeMe!

\subsection{Data Analysis}

Data were analyzed using memoing and thematic analysis. The first author wrote reflective research memos and summaries after each interview as a way to explore emergent themes and concepts within the data, explain research phenomena in context, and to facilitate conversations about the data within the research team [28-30]. Data were coded and reviewed by the first and second authors using open and descriptive coding to allow for codes and categories to emerge [29]. These codes and categories were collaboratively reorganized and winnowed into themes to ensure agreement within the codes. Memos were then reanalyzed with the themes generated from thematic analysis to contextualize and triangulate the data. Data source and investigator triangulation was utilized by collecting multiple forms of data (Table 3) and having a research team with different disciplinary backgrounds, research interests, roles, and ranks $[25,31]$. These differing backgrounds are described in the positionality statement below.

\subsection{Authors' Positionality}

The authors of this study consist of four faculty members from the IntE department (JAM, SML, GDH, DAC) and a postdoctoral research associate (LAG) hired under an NSF Revolutionizing Engineering and Computer Science Departments (RED) grant that the school of engineering received to develop "Changemaking" engineers by redefining the engineering canon as sociotechnical [32]. The course was a multidisciplinary effort developed by faculty with backgrounds in mechanical, electrical, civil, and engineering education. Our team included two White women, one Asian-American woman, one Latino, and one White man. The team consisted of three pre-tenure assistant professors, one tenured professor, and one postdoctoral scholar. These varying backgrounds allowed for an exploration on how energy was conceptualized within engineering disciplines. Sharing similar curricular and research interests, LAG added her background in engineering education and environmental engineering to collect and analyze data about the course through a lens of sustainability. During the Spring 2020 semester, LAG was introduced to the class as a researcher who would be conducting observations and interviews, and was in the classroom on a weekly basis until the transition to ERT [22]. By using the instructor as a gatekeeper, LAG was able to develop trust and rapport with the participants [25,33]. 


\subsection{Limitations}

Our study was limited in that we did not have all the students explicitly define sustainability as a classroom activity during the Spring 2020 semester. Students discussed multiple perspectives on efficiency through active learning, while the definition of sustainability was implicitly understood and thus multiple perspectives and definitions persisted. Student perspectives on sustainability were interpreted through their written assignments and interview data, which have different contexts and were not discussed together as a class in the way efficiency was. In this way, we could have been sending or reinforcing messages about efficiency and sustainability through classroom practices. Additionally, these results must be viewed in light of the transition to ERT and the global COVID-19 pandemic. Student work was considered both before and during ERT, and semi-structured interviews were conducted after the start of the pandemic. Perspectives on energy, sustainability, and climate change could have been influenced by the unprecedented situation where the cities and countries all over the world were under lockdown. Lastly, this study was conducted on a newly developed course at a private faith-based university within the Western United States with a focus on teaching, where engineering students receive a BS/BA and take a liberal arts core curriculum. Thus, our results may not be generalizable to engineering departments within public institutions. However, some of the results may be transferable to other engineering programs which also reinforce dominant discourses about engineering. Our sample size was too small to explore variations based on categories such as sex or race, etc. Future research is needed to explore these differences.

\section{Results}

Students expressed interest in sustainability (renewable energy in particular), but had incomplete, competing, and sometimes contradictory definitions of sustainability. Most students prioritized technical and economic aspects in design, mentioning environmental aspects as secondary, and social factors as an afterthought or not at all. Some students conceptualized sustainability by equating it with efficiency. This coincided with student definitions of efficiency which were strictly technical and focused on minimizing "waste" and maximizing the usefulness of resources. This conceptualization often ran contrary to their initial understanding of renewable energy (e.g., solar), leading to their surprise after realizing that renewable energy sources such as wind power were not as efficient as they initially believed. Students also described how energy must be useful and not wasted. While they expressed that the safety and waste disposal limitations of nuclear energy could be overcome with new technology, they did not give wind energy the same benefit of the doubt and focused on the economic costs and inefficiencies. In Table 4, we describe three major themes that emerged from our analysis: (1) defining efficiency, (2) equating sustainability with efficiency, and (3) the social aspect of sustainability. The three themes are listed, described, and examples found in the data are provided. These themes are discussed at length in the section below.

Table 4. Summary of Results.

\begin{tabular}{cll}
\hline Theme & \multicolumn{1}{c}{ Description } & \multicolumn{1}{c}{ Evidence } \\
\hline Defining Efficiency & \multicolumn{1}{c}{$\begin{array}{l}\text { Students were highly focused on } \\
\text { efficiency even when not prompted. } \\
\text { vs. output, minimizing costs while } \\
\text { maximizing resources, reducing } \\
\text { waste, and accomplishing a task at a } \\
\text { faster rate (e.g., less time) }\end{array}$} & $\begin{array}{l}\text { Studitized technical and } \\
\text { economic factors that increase } \\
\text { efficiency within engineering } \\
\text { design. }\end{array}$ \\
& & $\begin{array}{l}\text { Economic cost was frequently } \\
\text { paired with efficiency for students. }\end{array}$ \\
\hline
\end{tabular}


Table 4. Cont.

\begin{tabular}{|c|c|c|}
\hline Theme & Description & Evidence \\
\hline Equating Sustainability and Efficiency & $\begin{array}{l}\text { - Students equated efficiency with } \\
\text { sustainability, seeing both concepts } \\
\text { as reduction of waste and } \\
\text { maximizing the desired output. } \\
\text { Sustainability is not possible } \\
\text { without being efficient. } \\
\text { Energy is a resource that must be } \\
\text { useful and all "waste" minimized } \\
\text { otherwise it is not sustainable. } \\
\text { Anything creating profit is useful } \\
\text { and everything else is "waste". } \\
\text { Evolving perceptions of energy } \\
\text { sources when put in the context of } \\
\text { efficiency. }\end{array}$ & $\begin{array}{l}\text { - Students considered the } \\
\text { environmental aspects of } \\
\text { sustainability through the impact of } \\
\text { cost (i.e., wasted resources). } \\
\text { - Students shifted from focusing on } \\
\text { the environmental benefit of } \\
\text { reducing carbon emissions to the } \\
\text { "wasted" energy when converting } \\
\text { renewable sources such as wind and } \\
\text { solar into energy. } \\
\text { Students embraced nuclear energy } \\
\text { for its efficiency and were able to } \\
\text { justify social (e.g., safety, risk of } \\
\text { meltdown) and environmental (e.g., } \\
\text { waste disposal) through the } \\
\text { economic benefits of greater } \\
\text { efficiency. They did not consider } \\
\text { these social and environmental } \\
\text { issues an impediment to } \\
\text { implementing nuclear energy. }\end{array}$ \\
\hline The Social Aspect of Sustainability & $\begin{array}{l}\text { Students were aware of and could } \\
\text { describe social aspects of } \\
\text { sustainability, but they prioritized } \\
\text { technical, economic, and sometimes } \\
\text { environmental factors over social. }\end{array}$ & $\begin{array}{l}\text { - Students could only superficially } \\
\text { integrate social aspects of } \\
\text { sustainability into engineering } \\
\text { problem solving. } \\
\text { Students instinctively prioritized } \\
\text { technical aspects that improved } \\
\text { efficiency, suggesting a hierarchy } \\
\text { within the three aspects of } \\
\text { sustainability that puts economic } \\
\text { interests over environmental with } \\
\text { social being last. }\end{array}$ \\
\hline
\end{tabular}

\subsection{Defining Efficiency}

At the beginning of the course, students were asked to personally define efficiency. Their responses ranged from equations for measuring efficiency, to minimizing costs and maximizing resources such as time, materials, and energy, to describing it as an overall goal or objective. For example, one student described efficiency through a textbook-like definition by writing, "Efficiency is how well something converts its input to its output. Efficiency is out of $100 \%$. Efficiency is a measure of extent to which input [is] converted to output". Similarly, another wrote, "A ratio of how much of a thing something uses to how much output it produces input vs. output". The majority of students included elements of minimizing or not wasting resources. For example, one student stated, "Efficiency is doing the most you can with what you are given and tying to limit the waste on anything including time, work, or resources." Another defined efficiency as, "Carrying out a task using few resources to produce a large quantity of anything, but also taking the least amount of time." Students specifically described resources such as time, energy, materials, and finance (i.e., cost). Time, however, was the most frequently listed resource in need of conservation. In essence, many students saw efficiency as a measure of effectiveness or accomplishing a goal or completing a task in the least amount of time. Another student exemplified this by stating, "Efficiency is the ability to accomplish a goal or task at a faster rate, or with the fewest/sustainable resources. Perhaps at the cheapest cost." The majority of student definitions of efficiency were more nuanced and contextual than as typically defined through equations. Instead, they integrated principles of sustainability in the minimization of resources related to economic cost such as time and energy. This conceptualization became more refined throughout the course. 
Even when unprompted, students frequently focused on efficiency, which they linked to the optimal use of resources (i.e., minimizing waste, maximizing output). For example, on the first homework assignment, students were required to identify two key topics that would still impact the way they see the world in five years. The majority of responses (13 out of 17) specifically mentioned efficiency. One student focused on getting more output from renewable energy. They stated:

Two key topics I think will impact the way I see the world in five years are what source we get energy from and how to use energy more efficiently. [ . . . In order to better use our renewable resources and get the most output from them we will need to figure out how to use this energy more efficiently, whether it be how the energy from renewable resources is collected or how it is used after its delivered to the user. Maybe the generation of energy from renewable resources will become more efficient, or maybe the products we use that require energy will become more efficient-hopefully it is both. (Unknown, Homework)

These descriptions went hand in hand with a focus on optimizing and improving energy technologies. Many students saw the role of engineers not only as problem solvers but in improving and optimizing products or designs.

During their interviews, students were given an open-ended and purposefully vague prompt to imagine they were designing a new power installation, and asked to list the information they would want to inform their design. The students predominantly mentioned technical specifications that would result in the most efficient generation of energy first before considering other factors such as environmental, social, and economic. For example, Rachel responded to the prompt by first stating:

Probably the location of it, like we talked about [in this] class. If you were to use a different solar panel or wind energy, maybe the location is the most important to that. Who will be using it, how much energy needs to be produced in a day. So, who's going to get the power, the total efficiency of it, and the materials that might go into it. (Rachel, Interview)

When pressed further about material considerations, she brought up the materials used in solar panels and how they could have different efficiencies and costs. When asked to define efficiency in this context, she responded, "Like how much power is being used compared to the input and the output. And how much is being used towards electricity and usage". This definition of efficiency is more oriented towards input versus output rather than reduction of resources. While Rachel did include economic considerations in her response, her focus was clearly on the most efficient design. Cost was frequently paired with efficiency for students. For example, Lexie responded to the same prompt by saying:

I definitely would want to know about the climate of the surrounding area, if it's going to be inside or outside. [ . . ] Price. I'd definitely want to know price. Materials that I would need to use. What kind of drawbacks there will be if something goes wrong, maybe. Oh, gosh, [the question is] so vague. Man, maybe how big it is, how much space is it taking up. Does it need to look aesthetically pleasing, kind of like the EnergiPlant? How much power do I need to be producing? How efficient it is, stuff like that.. (Lexie, Interview)

As in their definitions of efficiency at the start of the semester, students also mentioned environmental factors in their response to this prompt. These environmental factors were often superficially explored, vague, or subsumed into considering renewable energy sources such as wind and solar. For example, Tito answered the question similarly to other students by listing technical factors that contribute to an efficient design and considered renewable energy sources such as wind, solar, and hydroelectricity. When asked to elaborate about specific environmental factors he would consider, Tito responded:

So I feel like you want to know kind of the environment that they're in [... ] because I think if it's not in a windy area, or it's kind of in a place that doesn't get sun all that 
often, then it would kind of affect whether you'd want to be solar. Because if it's in a place that's open and gets sun a lot of hours a day, then solar would probably be the way to go just because you're going to have the most efficient way to get it. And, well, you want to know the cost of each system being implemented. The cost and the environment. [ . . . I I mean, yeah, I really feel like it's kind of a weather factor if you want to go with the most efficient, renewable sources. (Tito, Interview)

Tito only mentioned renewable power sources, typically associated with sustainability and the environment, in his response. When he was asked if renewable energy was important to him, he stated that the class opened his eyes about the negative impacts of using coal and "really bad sources of energy". He continued, "So, it gets me thinking, 'Wow, we really do need to take a step back and look at what we are doing, why we're using so much of this source that is just polluting and killing the world.'" Tito described the environmental importance of using renewable energy sources, but his response to the open-ended prompt of designing a power installation with no numbers or constraints only detailed technical factors associated with the environment that would make the design the most efficient. Environmental issues and impacts that renewable energy sources are meant to address were reframed by the students as efficiency and optimization. Considering this and how students defined efficiency, it is not surprising that some students directly equated sustainability and efficiency.

\subsection{Equating Sustainability and Efficiency}

For some students, efficiency and sustainability were closely linked. Sustainability was not possible without efficiency. For example, a student with a sustainability concentration, Chandler, discussed what engineering personally meant to him in his interview and mentioned his interest in solving environmental problems and making things more sustainable and efficient. When asked to elaborate what he meant by this by defining efficiency and sustainability, he easily provided a definition of efficiency, but struggled with sustainability. He said:

To me, I think [efficiency and sustainability] go together. For something to be sustainable, it has to be somewhat efficient. I would say efficiency is just getting the most out of something with the least amount of waste. And sustainable is-I don't know-pretty similar, in my opinion. But sustainable ... I don't know how to describe it without using the word, but just being able to sustain and yeah, I don't know, similar to efficiency, the least amount of waste, most amount of output. (Chandler, Interview)

Chandler equated efficiency with sustainability, seeing both concepts as reduction of waste and maximizing the desired output. By reducing the amount of resources used, a design could be made more efficient. Another student with a sustainability concentration, Peter, also linked sustainability and efficiency. During the power installation question in his interview, the first source of energy he mentioned was hydroelectricity. Peter rejected this energy source as a possibility because the economic cost could be prohibitive, depending on the client's needs. He further justified not using this energy source by considering how a hydroelectric dam would impact the environment (e.g., wildlife). After eliminating hydroelectricity as a source of energy he considered other renewable energy sources such as solar and wind, and would present these options to a hypothetical client based on cost and how much space they would take up. When prompted for other factors he specifically mentioned efficiency and power requirements and how they would determine how many solar panels to use or the size of a wind turbine. When asked what type of energy sources he preferred based upon his sustainability concentration, he compared renewable energy sources based upon their costs and efficiencies. He said:

I like solar in general because it just kind of is relatively low-profile. I don't know. It's just a really simple way of turning solar radiation to electricity, and hydroelectric wouldn't necessarily be as consistent because if there were a drought that year or if it did wash out, it could be like hundreds of thousands of dollars to repair. And then wind is I think a little 
more variable than the solar radiation when you have a really windy day which could potentially break the windmill [ ... ] So, you got a really fine line for maximum efficiency and then breaking [the windmill]. Solar seemed more consistent.. (Peter, Interview)

This response focuses on the technical and efficiency aspects of renewable energy sources with considerations of cost, but omits or only superficially considers social and environmental aspects. When environmental aspects are mentioned (e.g., drought) they are considered through the impact of cost (e.g., repair). Other IntE students with concentrations in sustainability likewise brought up efficiency and sustainability together. When asked what topic would influence the way they saw the world in five years, one student responded:

One thing that will stick with me from class this week is the inefficiency of energy in the US. I had never really thought much about the energy we consume every day and the process to actually use it. I had just assumed all the energy we used got utilized. Knowing we really only get percentages of what goes in, sometimes small percentages, inspires me to find new and better ways to use energy. My focus is sustainability so hopefully with more focus on renewable energy I will be able to go further with this. (Unknown, Homework)

This student shows interest in how efficiently renewable energy is utilized, deliberately bringing up their sustainability concentration. When considering renewable energy sources, it is clear that the optimal use of resources (i.e., low cost, maximized output) influenced students' conceptualizations of sustainability.

\subsubsection{Energy Must Be Useful and Not Wasted}

When efficiency and sustainability are conceptualized together, energy becomes a resource that must be useful and all "waste" must be minimized at all stages (e.g., capture, conversion, use). Students frequently used words such as "harnessed" when describing using energy sources, often in the context of taking a natural resource and using it for human purposes. When sources of renewable energy (e.g., the sun, water, wind) were not used to their full potential, students saw this as being inefficient and wasteful. For example, one student mentioned an energy flow chart (i.e., Sankey diagram) shown in class and commented, "[ ... ] we see that more energy is wasted, instead of being converted into useful and efficient energy. This impacts the way I see the world in five years. [... ] Each primary energy has its pros and cons, and I think that it's important to see those advantages and use them to its fullest so that no resources go to waste, especially if they are not renewable." Energy had to be utilized efficiently both on a large scale (e.g., how efficiently renewable energy sources are converted to useful electricity) and on a personal scale (e.g., personal electricity use). For example, one student commented that one topic that would impact the world in five years was the "general lack of efficiency when it comes to energy. I think that knowing how much energy is wasted every time I use electricity or drive a car will allow me to be much more mindful as I choose how to live my adult life." Another student responded to the same question, "[ . . ] I never realized how much energy was wasted in comparison to our consumption. It made me realize the heavier impact of how damaging fossil fuels can be, but also the shortfalls of renewable energy as well."

At the same time, using this energy efficiently (i.e., not wasting resources) was considered necessary to be sustainable as well. When asked to explicitly define sustainability in his interview, Peter verbally navigated the competing aspects of sustainability and how they related to efficiency. He said:

Because [sustainability] kind of comes back to energy consumption even if energy is coming from solar uses, it's still technically not as sustainable to be wasting that energy. Say you have the lights on all day and it's all coming from solar, then it's technically zero carbon emissions, but you could be using that energy elsewhere if you weren't using the lights all day. So that's something kind of interesting I didn't think about until [the instructor, GDH] started talking about how solar energy-I mean, in our minds, it's 
just like the perfect solution. It's 100\%, I mean, it's only like $23 \%$ efficient, max, but it's zero percent carbon emissions and we're not using any fossil fuels. But then he talked about how we need to recycle the solar panels after like a 25-year lifespan and that's not really publicized at all. You just think of this infinite power source, the sun and we're just wasting all that energy that's hitting the earth's surface and then we throw solar in there and get all this energy we've never harnessed before, but it was interesting to think about how there's still negative effects from solar. I think there's pollutants in the fabrication process of solar as well and I never thought about that either. (Peter, Interview)

Peter described how the class altered his perception of renewable energy and sustainability in light of efficiency. His preconception of solar power being the "perfect solution" was challenged, adapting from a focus on reducing carbon emissions to the inefficiency of converting solar energy and other environmental considerations involved in the manufacturing of solar panels.

\subsubsection{Evolving Views of Solar and Wind Energy}

Solar and wind energy were frequently discussed in homework reflection questions and student interviews in relation to their efficiency. While these energy sources were initially lauded for being environmentally conscious and reducing impacts of climate change, students described how they now understood why such energy sources were utilized to such small degrees in the current United States energy landscape because of their lack of efficiency. This was especially salient for wind energy, which many students were critical of. When reflecting on how the class material on wind energy changed their perspective, 14 out of 17 students mentioned efficiency in their responses, predominantly commenting on wind turbines' inefficiencies and issues that inhibit wind energy's ability to maximize its output. For example, one student wrote:

I used to think wind power was so efficient and always wondered why it's not used as a main source of energy but I now know that harnessing wind is not as easy as it seems as it can be very inefficient. In my opinion, wind energy will be very important in the future because finding a way to make it more efficient will allow us to mitigate the amount of fossil fuels we generate. (Unknown, Homework)

This student and others wrestled with balancing the environmental benefits of using a relatively inefficient and unreliable source of energy compared to fossil fuel sources. However, the inefficiencies of wind energy also influenced how students perceived the usefulness of such energy sources. This was most apparent when students discussed the EnergiPlant [34]. The EnergiPlant is a small structure on campus that collects solar and wind energy and provides seating and outlets for charging electronic devices. While students appreciated the EnergiPlant as an educational tool to learn about wind and solar energy, they were less impressed with the structure after learning about its inefficiency. One student commented about the EnergiPlant in their homework:

I never thought about how much wind would be needed to produce an adequate amount of energy. As we did a practice problem on estimating the amount of energy the EnergiPlant could capture, it was still surprising to see very little energy produced. It is difficult to produce a large amount because it is impossible to have perfect efficiency for each component. Furthermore, the placement of the EnergiPlant is poor because it is not able to catch that much wind. It makes me wonder how practical the windmill actually is. [... I I think that wind will always be a part of the energy landscape, but I question if it will ever play a larger role. While there are a number of wind farms already in the world, it is difficult to make it onto one of the essential energy sources because of how unreliable it is. Wind is not a constant source of energy, but in our modern day we require a large amount of energy. (Unknown, Homework)

Students also commented on the EnergiPlant in their interviews. For example, when asked what about the class resonated or "clicked" with him, Chandler responded: "I think using the [... ] EnergiPlant, that really clicked and resonated with me because it looks like 
this pretty cool, not cheap thing, but then, when we look at the specifications of it and what it's actually doing, it's like is it really that efficient or even useful?" (Chandler, Interview). James also commented on the usefulness of the EnergiPlant after analyzing it as a class activity. When discussing the EnergiPlant as the most interesting thing about the course, he said, " ... this machine was designed ... for [the university] and no one uses it. And so, I started to ask questions like why does no one use it and why did we get this machine ... ?" (James, Interview).

These responses point to a shifted perception of renewable energy when specifically viewed through the lens of efficiency. When asked about what renewable energy source she was most interested in, Lexie stated:

I think I really like the idea of solar, but it seems a lot less efficient than I would hope. We were talking about... if a solar panel is in series and it gets shaded even a little bit, it's so much less efficient. And so, it makes you wonder, "Oh, okay, I guess that makes sense why it's not our number one thing that we use." It also depends where the sun is during the day-the angle that it's making in the sky, which I never really thought about either. So, I don't know. It makes sense why our main energy source is what it is and why we're polluting the world. (Lexie, Interview)

One student went so far as to claim that this perception of viewing energy through this efficiency perspective is what differentiates engineers from non-engineers. She said:

I think an engineer is just able to see things in a big picture scope and being able to connect many parts of different problems and kind of piecing together what a possible solution is but also realizing the constraints that might limit you from having a solution. Because I know people who aren't engineers might wonder, 'Why don't we have 100\% renewable energy? It's cheap. It's out there. Why are we still using natural gas or why we still using coal?' But as engineers, we know it's not as easy to contribute $100 \%$ of our energy production from renewables because of certain constraints. We can't all have solar power plants everywhere, or even wind farms everywhere, due to certain theoretical constraints. (Rebecca, Interview)

Rebecca implied that engineers operate under bounded conditions that are both scientific and defined through problems that are to be solved. This perspective can also influence how certain issues or problems related to energy can be engineered away if the output is worth it. This perspective is most apparent in how students discussed nuclear energy vs. wind or solar energy.

\subsubsection{Embrace of Nuclear Energy}

Students were introduced to nuclear energy later in the semester and engaged with multiple perspectives on nuclear power as an energy source $[35,36]$. Students' responses to nuclear energy were predominantly positive, seeing it as a viable and environmentally friendly alternative to fossil fuels and the efficiency drawbacks of solar and wind energy. While environmental benefits were superficially considered or implicit in discussions of wind and solar, students provided specific examples of how coal particulates impacted human health and emissions from burning coal contributed to climate change, which was used as justification for ranking nuclear energy over coal. Yet, when students described high profile social issues associated with nuclear energy (e.g., safety, meltdowns, waste disposal), nearly all did not consider them an impediment to implementing nuclear energy. For example, when asked about his personal view on nuclear energy, Robert responded:

I am definitely pro nuclear and nuclear plants being built in United States because it is the only power source that has the ability to produce energy at the same rate as fossil fuels and coal. No matter how much windmills and solar panels we put up, it will not create a consistent energy source. I was skeptical about nuclear energy as well based on the past historical events, but technological developments have made these power plants much safer by having a walkaway safety backup. This means when there is an accident, the power plant will immediately shut down without any human intervention. With a 
safer power plant, global warming, climate change, and lives lost to coal particulates will be saved. (Robert, Homework)

Students acknowledged the safety issues with nuclear energy but were quick to point out ways these safety measures could be included in engineering design, stating "more progress has been made to avoid situations such as Chernobyl where there is much less of a chance of a reactor meltdown" (Carmen, Homework). Chandler also considered this and stated that accidents are inevitable, "Accidents will always happen, but new technology in nuclear could make accidents much less catastrophic than what has happened in the past." (Chandler, Homework). He also extolled the environmental and social benefits of reducing greenhouse gas emissions, creating jobs, and benefiting the economy. Students assumed that technological progression would feasibly occur to overcome the issues of safety related to nuclear energy, but they did not give renewables such as wind power the same benefit of the doubt. Gloria stated, "As we develop better nuclear technologies, they become safer and more reliable. While these methods aren't perfect, they will lead to many fewer deaths than coal and natural gas currently do and can be developed and changed as technology moves forward" (Gloria, Homework,). While students expressed that wind energy technology would inevitably progress as well, they were much less enthusiastic about this prospect or only considered it useful in specific contexts such as out in the ocean. One student who thought the environmental and safety factors were too important to be overlooked wrote:

I agree that nuclear is a relatively efficient and carbon neutral energy source that we should consider. However, the main downsides to nuclear energy-large meltdowns and nuclear waste-are in my opinion too great to overlook. Even though nuclear energy has killed less people overall, the two main problems to nuclear still negatively hamper countries and harm people years and decades after major incidents. Renewables, especially wind and solar, have made great technological strides in the past decade, and I agree with Jaczko's argument that we should focus more towards newer energy sources that are safer and easily deployable [35]. From my perspective, the future of energy is in improving renewables, not building nuclear power plants. (Ross, Homework)

Unlike his peers, Ross' response prioritized the social aspect of sustainability in light of other arguments about the efficiency of nuclear and the possibility of engineering environmentally friendly solutions.

\subsection{The Social Aspect of Sustainability}

Social aspects of sustainability were not mentioned to the same frequency or depth as economic or even environmental aspects. Students prioritized technical aspects of design in their responses to the open-ended power installation question during the interviews. They mainly described tradeoffs between economic and environmental factors in their curricular data and other questions during the interviews. For example, when specifically asked about tradeoffs engineers might consider when choosing an energy source for a power station Mario stated, "The cost of an energy source is a very important factor. Another big consideration should be for the specific setting and arrangements what form is the energy is going to be consumed in and what the most efficient process. Lastly consider environmental impact of energy source and which would be least detrimental to environment." (Mario, In-class prompt). Despite this prioritization, students did include social aspects in some cases. For example, in her response Clara first mentioned cost, efficiency, and greenhouse gas emissions before ending her statement by bringing up the social issue of using conflict minerals. It should be noted that these students were introduced to the topic of conflict minerals in another required Integrated Engineering course [37], and were able to apply it to this class. Other social issues students mentioned included how the energy source affected the community, perceptions of safety, community displacement, and income and affordability of the energy source. In some cases, students only listed environmental and social tradeoffs. For example, Roger responded to the tradeoff prompt by stating: 
Engineers should overall consider the environmental impact and energy production value when deciding on a source of energy for a new power station. They need to decide on whether the fuel source is sustainable and clean in terms of emissions and waste, as well as evaluating the impact on local wildlife and environmental structures (i.e., how will using a natural water source as cooling affect the entire ecosystem). Additionally, they have to make sure that this will actually benefit the local community in jobs and have reasonable energy output per cost and size of plant (material use). (Roger, In-class prompt)

While students rarely mentioned social considerations first when given a design prompt, they were clearly aware of them. During the interview when asked about additional information needed to design a hypothetical power installation, Rebecca provided a nuanced response that considered environmental, social, and economic factors of sustainability. She said:

And then also considering not only the cost and the datasheets and the consumer, but also thinking about sustainability and thinking how this might impact the community or longterm consequences. [ ... ] Well, coal, there's so many cancerous effects and everything when you breathe it into your lungs. And carbon emissions and then hydroelectric dams would impact the animals that would possibly live in that environment. Versus solar may be expensive, but in the long-term could save you a lot of money, and the only concern I would think about is, where are these materials being harvested from for the solar panel?. (Rebecca, Interview)

One student even described tension between environmental and social aspects of sustainability when considering the example of the Three Gorges Dam. In homework 2, she wrote:

Something interesting that we learned in class this week was about the Three Gorges Dam. It was interesting to learn about the advantages and disadvantages of this system as it created a lot of controversy. With this hydroelectric power plant, it can be sustainable to the environment as it consumes renewable energy producing ... a ton of electricity. However, it can cause a lot of damage as it was seen in the flooding caused by this dam resulting in many casualties and destruction. It is relevant in my life because in the future, a hydroelectric dam could be a solution to using cleaner energy without having to depend on coal, natural gases, and more. However, the issues of human rights, location, and environmental impacts need to be taken into consideration as well. (Rachel, Homework)

While it can be difficult to detangle economic, environmental, and social aspects of sustainability, students such as Rachel showed a nuanced understanding of how these aspects not only intertwine but can be in opposition to each other.

\section{Discussion}

\subsection{Conceptualizations and Boundaries of Sustainability}

Historically, the definition of sustainability has had multiple and sometimes competing definitions which have led to misconceptions among students, instructors, and the public. Without defining sustainability with our students, we relied on their individual understandings and conceptualizations of the term which are informed by Western perspectives and engineering values. The Brundtland commission formalized the idea of three intersecting dimensions (e.g., social, economic, environmental) in 1987 [2], while the idea of a Triple Bottom Line of "People, Planet, Profit" was coined in 1994 in an attempt to integrate the social, environmental, and economic dimensions of sustainability that would better resonate with businesses who were making the choice to be sustainable (or not) [38]. For example, reframing the necessity of environmental compliance as becoming a more competitive business in a resource-limited future [39]. More recently, the United Nations adopted the Sustainable Development Goals in 2015, which include dimensions of people, planet, prosperity, peace, and partnerships to meet 17 goals with 169 specific targets [40]. 
While these conceptions are commonly cited, others argue that this model of three separate but interconnected aspects only reinforces unsustainable designs [4]. Further, these conceptions about sustainability are Western-centric and often ignore indigenous ideas, values, and conceptions of sustainability which contextualize humans and non-human entities (e.g., plants, animals) and do not consider them independent [41]. Indigenous conceptualizations of sustainability focus on establishing and maintaining a deep relationship with a sense of "place" and with sacred exchanges between humans and the resources needed for survival [42]. Whereas Western perspectives view resources as commodities to be utilized, indigenous perspectives view the use of resources as an ongoing exchange where the privilege of using these resources carries inherent responsibilities of stewardship and awareness of consequences for all living things [42]. Despite environmental and social considerations, Western sustainability frameworks are founded on maximizing profit and seek general knowledge applicable across systems through data-driven processes, rather than the place-based knowledge and local experts that indigenous perspectives value.

Sustainability resides on the boundary between engineering and non-engineering content $[5,43]$. Efficiency, however, is supported by the dominant discourses within engineering and upheld through rigor [44,45], depoliticization, meritocracy [17], and technological determinism [46]. Our students saw efficiency as a good in itself that should be prioritized, whereas their conceptualizations of sustainability were often based on efficiency. Because sustainability spans this boundary, its rigor and thus value are called into question in engineering [44]. The inherent multidisciplinary and interconnected nature of sustainability requires a diverse knowledge of topics such as pollution, climate change, social and cultural context, and environmental and social laws and regulations (all of which must be related to the engineering context) [47]. Because of this, sustainability is often taught broadly and theoretically rather than with concrete specific examples [48]. It can be difficult to implement in engineering classrooms because of the inclusion of difficult to quantify factors (i.e., social), concrete and contextual examples, and interconnected and holistic perspectives [47,49-52]. Exacerbating this issue in engineering is the perception that sustainability is a soft and undisciplined topic [48], which stands in opposition to "hard" and masculinized engineering fixated on efficiency [53]. Using an ecofeminist approach, researchers have argued that sustainability often occupies a marginalized space in engineering education that is tied to its feminization [54]. Sustainability is an example of a hierarchical dualism within engineering where White, Western, masculine, and technical perspectives are prioritized and privileged over others [43].

Traditional approaches to engineering problem solving require defining boundaries, constants, and variables. These boundaries are typically limited by time (e.g., a project timeline) and can omit long-term considerations and externalities, relegating social and environmental considerations to the status of external problems rather than incorporating them as integral to the issue [55]. Sustainability is a temporal problem with no endpoint (i.e., meeting the needs of the present without compromising the ability of future generations to meet their own needs). Students are trained to solve a specific problem or find a specific efficiency at a fixed point of time rather than to consider the needs of future generations. It is also important to note how boundaries are used to delineate what is useful and what is "wasted" in engineering. When considering energy, whatever creates a profit is considered useful, while anything outside of that is relegated to waste [56]. For example, the students used efficiency as a way to measure how much energy is wasted. They sought to maximize energy output and minimize "wasted" energy and conceptualized this as an environmental good. By being more efficient, they were preserving the environment through their careful use of resources. Additionally, the ways students grappled with their perspectives on energy sources (e.g., solar, wind) when learning how inefficient they were showed how this boundary operates in the classroom. Where an unmeasured environmental good was the primary motivator for their initial opinion of these renewable energy sources, they reframed that environmental good as "waste" using efficiency as a 
quantifiable measurement. In contrast, when they discussed nuclear energy, safety and waste disposal issues were something that could be engineered away.

\subsection{Engineering Problem Solving and Sustainability}

Consideration of boundaries also extends to the problem solving approach in engineering. We found that our students instinctively prioritized technical aspects that improved efficiency, suggesting a hierarchy within the three aspects of sustainability that puts economic interests over environmental with social being last. When technological aspects become hierarchical in problem solving within engineering, some interests are prioritized over others [57]. Because social impacts are more difficult to measure or calculate compared to technical, economic, and environmental factors, they may be left out of classroom problem solving. Thus, it is important to define the public good so that it is not an intangible afterthought [57]. Students showed which aspects took precedence in problem solving in their responses to the open-ended question about designing a power installation. For example, a dominant perspective in engineering is a "predict and control" approach which uses mathematics, science, and modeling to design technical systems with minimum uncertainty while a more integrated perspective would be a "community involvement" approach where participation of stakeholder groups is critical to the problem solving process and values local and contextualized knowledge [45]. The first factors students listed in the power installation question were typically technical or economic, interrelated with efficiency. Their problem solving approach, while considering client needs, focused on how the surrounding environment would affect the efficiency of the power installation over valuing local and contextual knowledge.

Efficiency and energy have been inextricably intertwined since the nineteenth century as scientists found ways to measure energy through heat and "work" and used these to explain the operating principles of steam engines [56]. Energy has quantities of inputs and outputs to measure and easily compare through efficiency. In contrast, our students struggled to incorporate aspects of sustainability that were intangible and immeasurable. They easily grasped technical considerations, economic costs, and environmental costs to an extent through the idea of minimizing waste, but social aspects mostly eluded consideration. Sustainability could be conceptualized as an economic and environmental issue, but was never primarily seen in social terms. Social aspects were the least mentioned by students, and when included, the statements were vague or an afterthought to a long discussion of technical factors. Similar results in a qualitative phenomenographic study of engineering students showed that the multiple aspects of sustainability exist in tension with each other. Students in that study primarily discussed technical solutions to sustainability problems and barriers to solutions. Additionally, they primarily focused on economic and environmental aspects of sustainability over social [13]. This focus on the economic and environmental aspects of the triple bottom line of sustainability was also found within a materials science course $[15,58,59]$. Even in industry, research shows that practicing engineers approached sustainable design from solution focused (i.e., finding a narrow solution to meet the client's needs) and problem focused (i.e., iteratively identifying and coconstructing the problem with the client to produce a set of requirements for the solution) ways. To address sustainability more holistically, practicing engineers had to take a social network focused approach (i.e., framing of the client's problem within the larger network of problems facing society), which requires a larger awareness of social issues [60].

\subsection{Efficiency and Social Considerations}

Our students showed an awareness of social issues related to sustainability (e.g., perception of nuclear safety, use of conflict minerals), but could not completely integrate them with engineering problem solving. That is, students were able to identify some the social implications of engineering work at a superficial level but did not critically analyze the unintended and long-lasting consequences of historically rooted, but neglected, inequities. This may make social aspects of sustainability less tangible to our engineering 
students than the technical calculations they perform daily. Likewise, Jiménez, Pascual, \& Mejía also asserted that issues of social justice, equity, and peace were difficult to relate to engineering because of their intangible nature [61]. Our students were given ways and ample practice to measure and assess energy efficiency in ways that reinforced dominant discourses within engineering, but because social aspects run contrary to these discourses, they may require extra attention to truly redefine engineering as sociotechnical as we intended. Within IntE, we strive to redefine engineering as a sociotechnical endeavor, which means our students are exposed to and required to consider social impact as an integral part of their engineering curriculum. Our students are taught to examine who benefits and who pays in engineering decision-making and design throughout their curriculum, especially in required courses such as User Centered Design and Engineering and Social Justice [62-65]. However, when presented with an open-ended design prompt such as the power installation question within the interviews, students predominantly fell back on technical and economic terms that related to efficiency before considering the environment second and social considerations in a limited capacity or not at all. Our results indicate that this not only requires a change in the broader curriculum but also a close and critical examination of how that curriculum is being delivered.

Narratives about energy have historically been closely tied to efficiency, not just in the sense of input vs. output as defined by textbooks but also efficiency of human labor [56]. Current conceptions of energy can be traced back to the Industrial Revolution and the use of burning coal to produce steam to power machines. While the dominant discourse in engineering is to value the most efficient and cost effective design (also replicated by our students), surprisingly, the use of coal-fired machines spread widely even though they were not less expensive than other forms of energy generation at the time [66]. Malm has argued that using coal allowed for the tighter control of labor in pursuit of profit. Coal was a fuel that "could be mobile, privatized, highly controlled, and burned all night in tireless prime movers" [65] (p. 29). Under the purported virtues of efficiency and eliminating waste, energy, efficiency, and human labor became enmeshed and reinforced through the science of energy [67]. Assessing efficiency through this scientific approach requires precise and technical measurements to calculate both work and waste, which align with technical engineering curriculum values and problem-solving approaches.

Our students conceptualized energy as something that must be harnessed and utilized, otherwise it is wasted (and thus inefficient and unprofitable). Their perceptions of energy sources such as wind and solar shifted once they became aware of the low efficiency of these sources. Despite their interest in minimizing climate change and protecting the environment, students could then justify why the U.S. energy landscape utilized such a low percentage of renewable energy sources. They were confident that technology would progress to mitigate the current challenges that affect wind and solar energy, but they were less willing to give them the benefit of the doubt compared to a highly efficient energy source such as nuclear energy. Students described the drawbacks and inefficiencies in terms of technical, economic, and environmental concerns for solar and wind energy in great detail, but only superficially addressed safety concerns (a primarily social concern), often stating the problem had already been solved. Additionally, students rarely mentioned the environmental impacts of storing nuclear waste, which are still unresolved, contentious, and expensive even after decades (e.g., the Yucca Mountain nuclear waste repository $[68,69])$ and have disproportionately negatively affected indigenous people [70]. They did not mention that technologies to reduce pollutants and increase safety for nonrenewable energy sources such as coal and oil already exist but are often not incorporated into design due to economic cost or poor enforcement of safety standards (e.g., the Dakota Access Pipeline spill [71]). It was important to students that technologies to remediate the social and environmental harm of using nuclear power as an energy source existed, but they did not mention if and how these technologies could realistically be integrated into design and everyday operational functions considering the greater cost associated with them. Even when aware of these factors, efficiency ultimately took precedence. Their 
responses indicated that the inefficiencies of solar and wind could not make up for the potential economic gains in the same way that nuclear energy could. However, whatever the justification, students did not consider who would pay for the benefits that nuclear energy would bring. More research is needed to elucidate these attitudes about energy sources and how they relate to efficiency and sustainability.

Dominant discourses about efficiency were unintentionally perpetuated within our course, and future research is needed concerning how efficiency narratives and dominant discourses in engineering are perpetuated within the engineering curriculum. It is clear that our students' conceptualizations of sustainability were Western-centric and viewed resources such as energy sources as commodities to be utilized. Sustainability is intertwined with the dominant engineering discourse of efficiency which privileges technical, masculine, western, and White conceptualizations. Alternate sustainability frameworks (e.g., indigenous, ecofeminist) which are place-based and use local context, value interconnectedness, and require stewardship, care, and communication, are far better suited to address all of the factors of sustainability, and most importantly the social considerations. In the most recent offering of the course, discussions concerning these complex definitions of sustainability took center stage. We also re-framed our discussions of efficiency to emphasize it is most useful when comparing within a particular technology type (e.g., between two models of wind turbines) as opposed to across different energy technologies (e.g., the efficiency of solar vs. wind). While it is difficult to completely escape dominant discourses in teaching engineering, a path to integrate different sustainability frameworks would include embracing a deeper sense of place with the goal of decolonizing both perspectives and environments [72].

\section{Conclusions \& Implications}

Students' conceptualization of efficiency as optimizing the use of resources and eliminating waste were linked to their perceptions of sustainability. This led some students to directly equate efficiency and sustainability, despite social aspects being incongruent with historical perspectives of efficiency. While unintended, the dominant discourse of valuing efficiency was reinforced within the classroom. This could be through leaving social considerations and sustainability undefined, implicit, and/or intangible within the classroom while technical calculations that reinforced efficiency were constantly practiced. There is a common discourse in engineering education that has contributed to the framing of engineering work as a field that creates profit, reduces regulation (i.e., exclusion of social and environmental contexts), and serves an ultimate capitalistic purpose. Even when intentionally seeking to disrupt dominant discourses, there is the possibility of replicating the status quo. The economic and environmental aspects of sustainability can fit within dominant engineering discourses because they derive their definitions from efficiency (i.e., maximizing profit, minimizing waste), but historically the social aspects can only be seen from a perspective of maximizing human productivity to be the most efficient possible. In science, energy is also called "work", which is no coincidence considering how steam power and the Industrial Revolution influenced the exploitation of and profit from labor. Even now, discussions of energy and climate change inevitably coincide with rhetoric concerning gaining or losing jobs in coal or renewable energy. As engineering educators, we must be more critically conscious of how our curriculum and pedagogy send messages about what is valuable to our students. We may be inhibiting true sociotechnical integration and limiting our students' ability to address the social and environmental aspects of sustainability by creating predetermined boundaries at the expense of the marginalized.

Supplementary Materials: The following is available online at https:/ / www.mdpi.com/article/ 10.3390/su13137188/s1, Document S1: Supplementary Material: Questions and Prompts from Semi-structured Interviews, Homework, and In-class Prompts Used for Analysis

Author Contributions: Conceptualization, L.A.G., J.A.M.; Methodology, L.A.G.; Validation, L.A.G., J.A.M., S.M.L., G.D.H., D.A.C.; Formal Analysis, L.A.G., J.A.M.; Writing-Original Draft Preparation, 
L.A.G.; Writing-Review \& Editing, L.A.G., J.A.M., S.M.L., G.D.H., D.A.C.; Funding Acquisition, S.M.L., G.D.H., D.A.C., J.A.M. All authors have read and agreed to the published version of the manuscript.

Funding: This material is based upon work supported in part by USA National Science Foundation (NSF) grants 1836504 and 1519453. Any opinions, findings and conclusions or recommendations expressed in this material do not necessarily reflect those of NSF.

Institutional Review Board Statement: The study was conducted according to the guidelines of the Declaration of Helsinki, and approved by the Institutional Review Board of the University of San Diego (IRB-2018-494, approved on July 5, 2018).

Informed Consent Statement: All subjects gave their written informed consent for inclusion before they participated in the study.

Data Availability Statement: The data are not publicly available due to privacy issues and to ensure confidentiality of the participants.

Acknowledgments: The authors would like to thank the students in the Integrated Approach to Energy class, particularly those who participated in interviews. We are grateful for the insights of our External Advisory Board for this grant.

Conflicts of Interest: The authors declare no conflict of interest. The founding sponsors had no role in the design of the study; in the collection, analyses, or interpretation of data; in the writing of the manuscript; and in the decision to publish the results.

\section{References}

1. National Academy of Engineering 14 Grand Challenges for Engineering in the 21st Century. Available online: http://www. engineeringchallenges.org/challenges.aspx (accessed on 1 May 2021).

2. The Brundtland Commission. Our Common Future: Report of the World Commission on Environment and Development; Hauff, V., Ed.; Oxford University Press: Oxford, UK, 1987; ISBN 019282080X.

3. Harris, J.M. Sustainability and sustainable development. Internet Encycl. Ecol. Econ. 2003, 1, 1-12.

4. Vanasupa, L.; Burton, R.; Stolk, J.; Zimmerman, J.; Leifer, L.; Anastas, P. The systemic correlation between mental models and sustainable design: Implications for engineering educators. Int. J. Eng. Educ. 2010, 26, 438-450.

5. Pawley, A.L. What counts as engineering: Towards a redefinition. In Engineering and Social Justice: In the University and Beyond; Baillie, C., Pawley, A.L., Riley, D., Eds.; Purdue University Press: West Lafayette, IN, USA, 2012; pp. 59-85.

6. Pawley, A.L. Universalized narratives: Patterns in how faculty members define "engineering". J. Eng. Educ. 2009, 98, 309-319. [CrossRef]

7. Ertas, A. Transdisciplinary Engineering Design Processes, 2nd ed.; John Wiley \& Sons: Hoboken, NJ, USA, 2018 ; ISBN 9781119474753.

8. Newberry, B. Efficiency Animals: Efficiency as an Engineering Value. In Engineering Identities, Epistemologies and Values: Engineering Education and Practice in Context; Christensen, S.H., Ed.; Springer: Berlin, Germany, 2015; Volume 2, pp. 199-214. ISBN 9783319161716.

9. Thind, M.P.S.; Tessum, C.W.; Azevedo, I.L.; Marshall, J.D. Fine particulate air pollution from electricity generation in the US: Health impacts by race, income, and geography. Environ. Sci. Technol. 2019, 53, 14010-14019. [CrossRef] [PubMed]

10. International Institute for Sustainable Development Life Cycle Costing: A Question of Value. Available online: https://ec.europa. eu/\%0Aenvironment/gpp/pdf/WP-LifeCycleCosting.qx.pdf (accessed on 12 March 2021).

11. International Organization of Standards ISO 14044:2006. Environmental Management-Lifecycle Assessment Requirements and Guidelines. Available online: https:/ / www.iso.org/\%0Astandard/38498.html (accessed on 12 March 2021).

12. Kedrowicz, A.A.; Blevins, M.D. Renewable and efficient? Mechanical engineering students' conceptions of sustainability and engineering. In Proceedings of the ASEE Annual Conference \& Exposition, San Antonio, TX, USA, 9-13 June 2012; pp. 1-8.

13. Kabo, J.; Nieusma, D.; Baillie, C. Engineering Students' Conceptualizations of Sustainability. In Proceedings of the Frontiers in Education Conference, Uppsala, Sweden, 21-24 October 2020.

14. Nordhaus, W.D. Carbon taxes to move toward fiscal sustainability. In Economists' Voice; Edlin, A.S., Ed.; Columbia University Press: New York, NY, USA, 2012; pp. 208-214.

15. Gelles, L.A.; Lord, S.M. Investigating using a "Social Impact Audit" tool to support students' decision-making in a Materials Science Course. In Proceedings of the Frontiers in Education Conference, Uppsala, Sweden, 21-24 October 2020.

16. Leydens, J.A.; Johnson, K.; Claussen, S.; Blacklock, J.; Moskal, B.M.; Cordova, O. Measuring change over time in sociotechnical thinking: A survey/validation model for sociotechnical habits of mind. In Proceedings of the ASEE Annual Conference \& Exposition, Salt Lake City, UT, USA, 24-27 June 2018.

17. Cech, E.A. Culture of Disengagement in Engineering Education? Sci. Technol. Hum. Values 2014, 39, 42-72. [CrossRef] 
18. ABET. Criteria for Accrediting Engineering Programs Effective for the Evaluations during the 2019-2020 Accreditation Cycle. Available online: https:/ / www.abet.org/accreditation/accreditation-criteria/criteria-for-accrediting-engineering-programs2019-2020/\#GC3/ (accessed on 2 May 2021).

19. Riley, D.M. Engineering and Social Justice; Morgan \& Claypool: San Rafael, CA, USA, 2008; ISBN 9781598296266.

20. Leydens, J.A.; Lucena, J.C. Engineering Justice: Transforming Engineering Education and Practice; John Wiley \& Sons: Hoboken, NJ, USA, 2017; ISBN 9781118757307.

21. Hoople, G.D.; Chen, D.A.; Lord, S.M.; Gelles, L.A.; Bilow, F.; Mejia, J.A. An integrated approach to energy education in engineering. Sustainability 2020, 12, 9145. [CrossRef]

22. Gelles, L.A.; Lord, S.M.; Hoople, G.D.; Chen, D.A.; Mejia, J.A. Compassionate flexibility and self-discipline: Student adaptation to emergency remote teaching in an integrated engineering energy course during COVID-19. Educ. Sci. 2020, 10, 304. [CrossRef]

23. Hoople, G.D.; Mejia, J.A.; Chen, D.A.; Lord, S.M. Reimagining Energy Year 2: Integrating CSPs into course development. In Proceedings of the ASEE's Virtual Conference, Online, 23 June 2020.

24. Thomas, D.R.; Hodges, I.D. Designing and Managing Your Research Project: Core Knowledge for Social and Health Researchers; Sage Publications: London, UK, 2010; ISBN 9781446289044.

25. Creswell, J.W. Qualitative Inquiry E Research Design: Choosing Among Five Approaches, 3rd ed.; Sage: Thousand Oaks, CA, USA, 2013; ISBN 9781412995306.

26. Longhurst, R. Semi-structured Interviews and Focus Groups. In Key Methods in Geography; Clifford, N.J., Valentine, G., Eds.; Sage: London, UK, 2003; pp. 117-132. ISBN 9788578110796.

27. Irvine, A.; Drew, P.; Sainsbury, R. 'Am I not answering your questions properly?' Clarification, adequacy and responsiveness in semi-structured telephone and face-to-face interviews. Qual. Res. 2013, 13, 87-106. [CrossRef]

28. Vogt, W.P.; Vogt, E.R.; Gardner, D.C.; Haeffeke, L.M. Selecting the Right Analyses for Your Data: Quantitative, Qualitative, and Mixed Methods; Guilford: New York, NY, USA, 2014; ISBN 978-1-4625-1576-9.

29. Saldaña, J. The Coding Manual for Qualitative Researchers, 3rd ed.; Sage: Los Angeles, CA, USA, 2016; ISBN 978-1-4739-0248-0.

30. Birks, M.; Chapman, Y.; Francis, K. Memoing in qualitative research: Probing data and processes. J. Res. Nurs. 2008, 13, 68-75. [CrossRef]

31. Johnson, R.B. Examining the validity structure of qualitative research. Education 1997, 118, 282-292.

32. Lord, S.M.; Olson, R.; Roberts, C.A.; Baillie, C.; Dalrymple, O.O.; Perry, L.A. Developing Changemaking Engineers-Year Five. In Proceedings of the ASEE's Virtual Conference, Online, 22 June 2020.

33. McGinn, M.K. Researcher-participant relationships. In The SAGE Encyclopedia of Qualitative Research Methods; Given, L., Ed.; Sage: Thousand Oaks, CA, USA, 2008; pp. 768-771. ISBN 978-141294163.

34. PrimoEnergy Plug in to Nature with the EnergiPlant. Available online: https:/ /www.primoenergy.com/products/energiplant/ (accessed on 5 May 2021).

35. Jaczko, G. I Oversaw the U.S. Nuclear Power Industry. Now I Think it Should be Banned. Available online: https://www. wash ingtonpost.com/outlook/i-oversaw-the-us-nuclear-power-industry-now-i-think-it-should-be-banned/2019/05/16/a3 b8be52-71db-11e9-9eb4-0828f5389013_story.html (accessed on 27 May 2021).

36. Schumacher, D. The New Fire. Generation Films. 2018. Available online: https://www.newfiremovie.com/ (accessed on 27 May 2021).

37. Lord, S.M.; Przestrzelski, B.; Reddy, E. Teaching social responsibility in a circuits course. In Proceedings of the ASEE Annual Conference \& Exposition, Tampa Bay, FL, USA, 16-19 June 2019.

38. Elkington, J. Enter the triple bottom line. In The Triple Bottom Line: Does it All Add Up; Henriques, A., Richardson, J., Eds.; Earthscan: New York, NY, USA, 2013; pp. 1-16. ISBN 9781849773348.

39. Elkington, J. Cannibals with Forks: The Triple Bottom Line of 21st Century Business; Capstone: Oxford, UK, 1997; ISBN 190096127X.

40. United Nations Department of Economic and Social Affairs. The 17 Goals. Available online: https://sdgs.un.org/goals (accessed on 5 May 2021).

41. Virtanen, P.K.; Siragusa, L.; Guttorm, H. Introduction: Toward more inclusive definitions of sustainability. Curr. Opin. Environ. Sustain. 2020, 43, 77-82. [CrossRef]

42. Kealiikanakaoleohaililani, K.; Giardina, C.P. Embracing the sacred: An indigenous framework for tomorrow's sustainability science. Sustain. Sci. 2016, 11, 57-67. [CrossRef]

43. Faulkner, W. Dualisms and hierarchies in engineering. Soc. Stud. Sci. 2000, 30, 759-792. [CrossRef]

44. Riley, D. Rigor/Us: Building Boundaries and Disciplining Diversity with Standards of Merit. Eng. Stud. 2017, 9, 249-265. [CrossRef]

45. Danielsson, A.T.; Gonsalves, A.J.; Silfver, E.; Berge, M. The pride and joy of engineering? The identity work of male working-class engineering students. Eng. Stud. 2019, 11, 172-195. [CrossRef]

46. Dafoe, A. Determinism: A typology, scope conditions, and a mechanism. Sci. Technol. Hum. Values 2015, 40, 1047-1076. [CrossRef]

47. Boyle, C. Considerations on educating engineers in sustainability. Int. J. Sustain. High. Educ. 2004, 5, 147-155. [CrossRef]

48. Leal, W. Dealing with misconceptions on the concept of sustainability. Int. J. Sustain. High. Educ. 2000, 1, 9-19. [CrossRef]

49. El-Zein, A.; Airey, D.; Bowden, P.; Clarkeburn, H. Sustainability and ethics as decision-making paradigms in engineering curricula. Int. J. Sustain. High. Educ. 2008, 9, 170-182. [CrossRef] 
50. Byrne, E.P.; Desha, C.J.; Fitzpatrick, J.J.; Hargroves, K. Exploring sustainability themes in engineering accreditation and curricula. Int. J. Sustain. High. Educ. 2013, 14, 384-403. [CrossRef]

51. Halbe, J.; Adamowski, J.; Pahl-Wostl, C. The role of paradigms in engineering practice and education for sustainable development. J. Clean. Prod. 2015, 106, 272-282. [CrossRef]

52. Allenby, B.; Allen, D.; Davidson, C. Sustainable engineering. Environ. Qual. Manag. 2007, 17, 17-26. [CrossRef]

53. Faulkner, W. "Nuts and bolts and people": Gender-troubled engineering identities. Soc. Stud. Sci. 2007, 37, 331-356. [CrossRef]

54. Rao, R.; Pawley, A.L.; Hoffmann, S.R.; Cardella, M.E.; Ohland, M.W. An ecofeminist grounded analysis of sustainability in engineering education: Skill set, discipline, and value. Int. J. Eng. Educ. 2013, 29, 1472-1489.

55. Bell, S. Engineers, society, and sustainability. Synth. Lect. Eng. Technol. Soc. 2011, 6, 1-109. [CrossRef]

56. Daggett, C.N. The Birth of Energy: Fossil Fuels, Thermodynamics, E the Politics of Work; Duke University Press: London, UK, 2019; ISBN 9788578110796.

57. El-Zein, A.H.; Hedemann, C. Beyond problem solving: Engineering and the public good in the 21st century. J. Clean. Prod. 2016, 137, 692-700. [CrossRef]

58. Gelles, L.A.; Lord, S.M. The Final Straw: Incorporating accessibility and sustainability considerations into material selection decisions. In Proceedings of the ASEE's Virtual Conference, Online, 25 June 2020.

59. Gelles, L.A.; Lord, S.M. Pedagogical considerations and challenges for sociotechnical integration within a materials science class. Int. J. Eng. Educ. 2021, 37. in press.

60. Mann, L.; Radcliffe, D.; Dall'Alba, G. Experiences of sustainable design among practicing engineers? Implications for engineering education. In Proceedings of the ASEE Annual Conference \& Exposition, Honolulu, HI, USA, 24-27 June 2007.

61. Jiménez, P.P.; Pascual, J.; Mejía, A. Educating engineers under a social justice perspective. Int. J. Eng. Pedagog. 2020, 10 , 82-97. [CrossRef]

62. Chen, D.A.; Chapman, M.A.; Mejia, J.A. Balancing complex social and technical aspects of design: Exposing engineering students to homelessness issues. Sustainability 2020, 12, 5917. [CrossRef]

63. Fledderman, B.; Mejia, J.A.; Chen, D.A.; Chapman, M.A. Drugs, alcohol, joblessness, and life style: Engineering students' perceptions of homelessness and implications for social justice education. In Proceedings of the ASEE Annual Conference \& Exposition, Long Beach, CA, USA, 27-30 June 2021.

64. Mejia, J.A.; Chen, D.; Chapman, M.A. Engineering as a challenging vocation: How students align personal values to the dominant engineering discourse. In Proceedings of the ASEE's Virtual Conference, Online, 22 June 2020.

65. Mejia, J.A.; Chen, D.A.; Dalrymple, O.O.; Lord, S.M. Revealing the invisible: Conversations about-isms and power relations in engineering courses. In Proceedings of the ASEE Annual Conference \& Exposition, Salt Lake City, UT, USA, $24-27$ June 2018.

66. Malm, A. Fossil Capital: The Rise of Steam Power and the Roots of Global Warming; Verso Books: Brooklyn, NY, USA, 2016; ISBN 9781784781323.

67. Karns, A.J. The Mantra of Efficiency: From Waterwheel to Social Control; John Hopkins University Press: Baltimore, MD, USA, 2008; ISBN 9780801886935.

68. Tyler, S.W. Are arid regions always that appropriate for waste disposal? Examples of complexity from Yucca Mountain, Nevada. Geosciences 2020, 10, 30. [CrossRef]

69. Macfarlane, A.; Ewing, R. Déjà vu for U.S. nuclear waste. Science 2017, 356, 1313. [CrossRef] [PubMed]

70. Endres, D. The rhetoric of nuclear colonialism: Rhetorical exclusion of American Indian arguments in the Yucca Mountain nuclear waste siting decision. Commun. Crit. Stud. 2009, 6, 39-60. [CrossRef]

71. Kennedy, M. Judge Orders Environmental Review of Controversial Dakota Access Pipeline. Available online: https://www.npr. org/2020/03/25/821643911/judge-orders-environmental-review-of-controversial-dakota-access-pipeline (accessed on 5 May 2021).

72. Johnson, J.T.; Larsen, S.C. A Deeper Sense of Place: Stories and Journeys of Indigenous-Academic Collaboration; Oregon State University Press: Corvallis, OR, USA, 2013; ISBN 9780870717239. 